\title{
RISCOS EM CADEIAS DE SUPRIMENTOS - ESTUDO DE CASO EM UMA EMPRESA PRODUTORA DE ETANOL, AÇÚCAR E BIOENERGIA
}

\author{
Mariana Barbero Ribeiro Goulart \\ mariana.brgoulart@gmail.com \\ Flavia Garcia Renales \\ flaviarenales@hotmail.com
}

Pontifícia Universidade Católica do Rio de Janeiro - Rua Marquês de São Vicente, 225, Gávea - Rio de Janeiro, RJ - Brasil 22451-900

\author{
Adriana Leiras \\ Coordenadora do Lab HANDs - Humanitarian Assistance and Needs for Disasters \\ Departamento de Engenharia Industrial, Pontifícia Universidade Católica do Rio de Janeiro - \\ PUC-Rio - Rua Marquês de São Vicente, 225 sala 950L - 22453-900, Gávea, \\ Gávea - Rio de Janeiro, RJ - Brasil 22451-900 \\ adrianaleiras@puc-rio.br
}

\begin{abstract}
Resumo
No atual ambiente de negócios mundial, as cadeias de suprimento vêm crescendo em complexidade. Este aumento, associado ao foco na melhoria da eficiência, pode levar a níveis mais elevados de riscos ao qual a cadeia está sujeita. Sendo assim, aumenta a probabilidade de uma ruptura impactar severamente o desempenho das mesmas. Cadeias de suprimentos resilientes têm sido apontadas como um meio para reduzir a probabilidade e a gravidade das interrupções nas redes de fornecimento. Apesar de existirem poucas evidências de como tornar uma cadeia de suprimentos resiliente, neste trabalho será estudado como a gestão de riscos em uma usina de produção sucroalcooleira pode influenciar o nível de resiliência da cadeia de suprimentos de uma empresa. O objetivo deste trabalho é destacar os principais riscos envolvidos neste tipo de negócio e avaliar como a empresa pode se posicionar quanto a sua resiliência. É realizado um estudo de caso em uma usina de produção de etanol, açúcar e bioenergia. A partir disso, foi feita a análise do nível de resiliência desta empresa e quais pontos poderiam ser aprimorados para maximizar sua eficiência.
\end{abstract}

Palavras-chave: Cadeia de suprimentos; resiliência; gestão de riscos; usinas sucroalcooleiras; vulnerabilidade

\begin{abstract}
In today's global business environment, supply chains are growing in complexity. This increase associated with the focus on improving efficiency levels can lead to higher risks to which the chains are subjected. Thus, increases the likelihood of a breakdown to severely impact their performance. Resilient supply chains have been identified as means to reduce the probability and gravity of disruptions in supply chains. Although there are few evidence of how to build a resilient supply chain, this work will study how the management of the risks that influence a power plant of sugarcane and ethanol can influence the level of resilience of a company's supply chain. The objective of this research is to highlight the main risks involved in this type of business and evaluate the company's resilience. The study is focused on power plants that produce ethanol, sugar and bioenergy. From this, was made an analysis of the level of resilience of the studied company and what points should be improved so that its efficiency was maximized.
\end{abstract}

Key-words: Supply chain; resilience; risk management; sugar and ethanol power plants; vulnerability 


\section{INTRODUÇÃO}

Com o aumento da competitividade global, aumentou-se a adoção de modelos de gestão de cadeia de suprimentos por parte de empresas de bens de consumo e serviços visando oferecer aos clientes melhor nível de serviço com diferencial competitivo. Em paralelo, aumentaram também as incertezas do mercado, que provocam significativas flutuações de demanda e clientes mais exigentes. Verifica-se, assim, a grande vulnerabilidade a qual as cadeias de suprimentos estão expostas e, por essa razão, as empresas devem ser cada vez mais resilientes, isto é, flexíveis e adaptáveis às mudanças do mercado e exigências dos clientes, tanto internos, quanto externos. Ao conceito de vulnerabilidade são associados riscos como: excesso ou falta de estoque, assim como falta de espaço para a estocagem; problemas com transporte; com os fornecedores; insucesso no lançamento de novos produtos; pirataria, entre outros, tornando a gestão da cadeia de suprimentos ainda mais complexa.

Para as empresas que já possuem modelos de gestão implantados, o maior desafio é mitigar riscos de ocorrências como seu atendimento, receita e relação com o consumidor, que podem macular a sua imagem, ou seja, a maneira como é vista aos olhos do mercado. As organizações globais estão ainda mais sujeitas às mudanças mundiais imprevisíveis, como desastres naturais, terrorismo e até situações de guerra, sendo assim, as rupturas nas atividades das cadeias são ainda mais frequentes e/ou iminentes.

Nestas situações, identifica-se que a gestão de risco eficaz é um diferencial competitivo. Sendo assim, esta gestão depende de situações particulares de cada tipo de indústria, de mercado e de empresa, onde, normalmente, as análises de riscos para a gestão da cadeia de suprimentos são feitas em termos de custos e nível de ameaça que tal risco representa para a cadeia. Estudar os riscos em uma cadeia de suprimentos é crucial para garantir que a proteção de vidas humanas seja prioridade em todos os planos; para definir papéis e responsabilidades; para orientar a elaboração e os procedimentos necessários em relação aos processos críticos; para assegurar que todas as áreas estejam cientes e participem; para garantir a continuidade do negócio e, ainda, garantir que uma solução logística resiliente seja bem estrutura levando em conta o maior número de cenários possíveis.

Neste contexto, o objetivo geral deste trabalho é analisar os riscos em cadeias de suprimentos e, especificamente, realizar um estudo de caso de empresa (denominada neste trabalho como Empresa X), cujas áreas de atuação são: produção de etanol, açúcar e bioenergia; e distribuição de combustíveis.

O estudo é focado nas usinas de produção de etanol, açúcar e bioenergia. Propõe-se a realização de um mapeamento de riscos através da análise das etapas da produção. A partir disso será feita a análise do nível de resiliência desta empresa e quais pontos poderiam ser aprimorados para que sua eficiência fosse máxima.

Além desta seção introdutória, este artigo é composto por mais quatro seções. A seção 2 apresenta a fundamentação teórica na qual se embasa este artigo. Na seção 3 é apresentado o estudo de caso na Empresa X, demonstrando a importância de toda empresa possuir um processo estruturado para gestão de riscos. Na seção 4 desenvolveu-se a conclusão e, por fim, na última seção, foi detalhada a revisão bibliográfica.

\section{REVISÃO BIBLIOGRÁFICA}

Esta seção apresenta o embasamento teórico para o artigo.

\subsection{GESTÃO DE RISCOS EM CADEIA DE SUPRIMENTOS}

Para a gestão de risco da Cadeia de Suprimentos, é preciso compreender três termos que serão brevemente discutidos a seguir: o risco, a vulnerabilidade e a resiliência na cadeia de suprimentos. Risco na cadeia de fornecimento pode ser definido como as variações na 
distribuição de possíveis fornecedores da cadeia de suprimentos (supply chain outcomes), derivados de uma probabilidade de ocorrência e os seus valores subjetivos. Esta definição realça as duas dimensões que caracterizam risco: impacto e probabilidade de ocorrência (Faisal et al., 2006). Assim, o risco está relacionado ao surgimento de eventos negativos que impedem à empresa de atender eficazmente à demanda de seu cliente.

Intimamente interligado com o conceito de risco está a noção de vulnerabilidade. Ela é definida como a existência de perturbações aleatórias que levam a desvios na cadeia de suprimentos e suas atividades normais, esperadas ou previstas, na qual causam efeitos negativos ou consequências (Svensson, 2000). A resiliência é definida como a habilidade de um sistema retornar para o seu estado original ou se adaptar a um novo estado desejado, depois de sofrer uma interrupção (Christopher e Peck, 2004). A capacidade de uma empresa de sobreviver depois de uma interrupção em sua cadeia de suprimentos está diretamente relacionada com o nível de resiliência estabelecido para sua cadeia (Likewise et al., 2005a).

O objetivo da gestão de riscos da cadeia de suprimentos é a proteção dos negócios de eventos adversos. De acordo com Haywood e Peck (2004), a primeira abordagem para atingir esse objetivo é representada pela introdução de amortecedores operacionais ao longo da cadeia de suprimentos (o excesso de estoque ou capacidade produtiva, backup de abastecimento, múltiplos fornecedores). Entretanto, estas estratégias de amortecimento tradicionais podem diminuir desempenhos operacionais e impactar negativamente em relação a vantagem competitiva.

O segundo método de gestão de riscos, chamado mitigação, baseia-se na análise dos processos, com o objetivo de reduzir a probabilidade de sua ocorrência. Por exemplo, propor treinamentos para um grupo de funcionários responsáveis por um determinado processo, visando uma melhor formação dos mesmos.

A última estratégia é a de enfrentar o risco através da introdução de planos de contingência que podem ser utilizados uma vez que ocorre um evento negativo. Norman e Jansson (2004) definem planos de contingência como planos de gestão de continuidade de negócios, isto é, planos e ações que fornecem modos alternativos de funcionamento para as atividades e processos do negócio que, se interrompidos, podem trazer um dano ou prejuízo para a cadeia de abastecimento.

Ainda de acordo com Norman e Jansson (2004), os planos de contingência podem ser divididos em: planos de resposta (reação imediata diante de um problema), planos de recuperação (ações necessárias para retomar as partes essenciais do processo ou de um negócio) e planos de restauração (reiniciando toda a organização). De acordo com Zolkos (2003), empresas de sucesso são aquelas que podem identificar e desenvolver planos de contingência para as várias fontes de risco que ameaçam a organização tanto internamente quanto externamente.

\subsection{CONSTRUINDO UMA CADEIA DE SUPRIMENTOS RESILIENTE}

Para Christopher e Peck (2004), gestores de cadeia de suprimentos se esforçam para alcançar os ideais de cadeias totalmente integradas, eficientes e eficazes de abastecimento, capazes de criar e sustentar uma vantagem competitiva. Para este fim, devem equilibrar as pressões de custo baixo e a necessidade de eficiência, com meios eficazes para gerenciar as demandas de serviços orientadas para o mercado e os riscos conhecidos de falhas da cadeia de suprimentos de rotina. A capacidade de uma empresa de sobreviver depois de uma interrupção em sua cadeia de suprimentos está diretamente relacionada com o nível de resiliência estabelecido para sua cadeia (Zsidisin et al., 2005).

Uma forma de atribuir uma melhor resiliência à Cadeia de Suprimentos é utilizar uma matriz resumo, que capta os vários níveis de riscos na cadeia (Figura 1). A ideia é que os gestores possam resumir suas avaliações quanto à resiliência dos processos nessa matriz, na 
qual cada quadrante captura um nível de resiliência inerente a cadeia, e mais importante, poderia servir de base para priorizar os esforços necessários na construção de resiliência.

Cadeias de Suprimentos vulneráveis, que têm um nível baixo de potencializadores de resiliência e alto nível de redutores de resiliência, são as cadeias mais problemáticas e, por isso, é preciso garantir uma maior atenção e recursos da empresa sobre essa rede. Estas cadeias de suprimento são particularmente vulneráveis e mesmo pequenas interrupções podem gerar graves impactos sobre as operações da empresa. Em relação a cadeias de suprimentos voláteis, com níveis altos de potencializadores de resiliência e alto nível de redutores de resiliência, estas são redes extremamente imprevisíveis e difíceis de gerir.

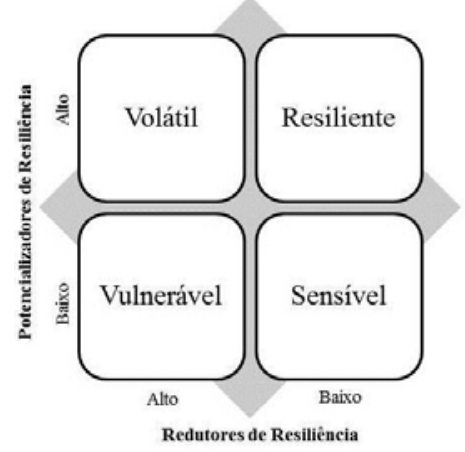

Figura 1 - Matriz de Nível de Resiliência (Blackhurst et al., 2011)

Quando uma interrupção ocorre em uma cadeia de fornecimento volátil, por exemplo, o sistema pode tanto absorver o rompimento de uma vez, como experimentar graves consequências em uma próxima vez. Por outro lado, as cadeias de fornecimento sensíveis têm baixos níveis de potencializadores de resiliência e baixos níveis de redutores de resiliência.

Em suma, a teoria diz que a situação ideal para cadeias de suprimentos resilientes é que elas tenham altos níveis de potencializadores de resiliência e baixos redutores de resiliência. Cadeias de suprimentos resilientes são capazes de absorver rupturas e voltar para condições estáveis rapidamente (Sheffi e Rice, 2005), o que poderia dar às empresas uma vantagem competitiva exclusiva (Christopher e Peck, 2004).

A partir destes conceitos, Blackhurst et al.(2011) elaboraram um quadro resumo (Figura 2) identificando os principais elementos redutores e potencializadores de resiliência. Este framework pode ser utilizado para avaliar o atual nível de resiliência da Cadeia de Suprimentos de uma empresa, bem como os seus segmentos. Em essência o quadro pode ser entendido como um nivelador de resiliência.

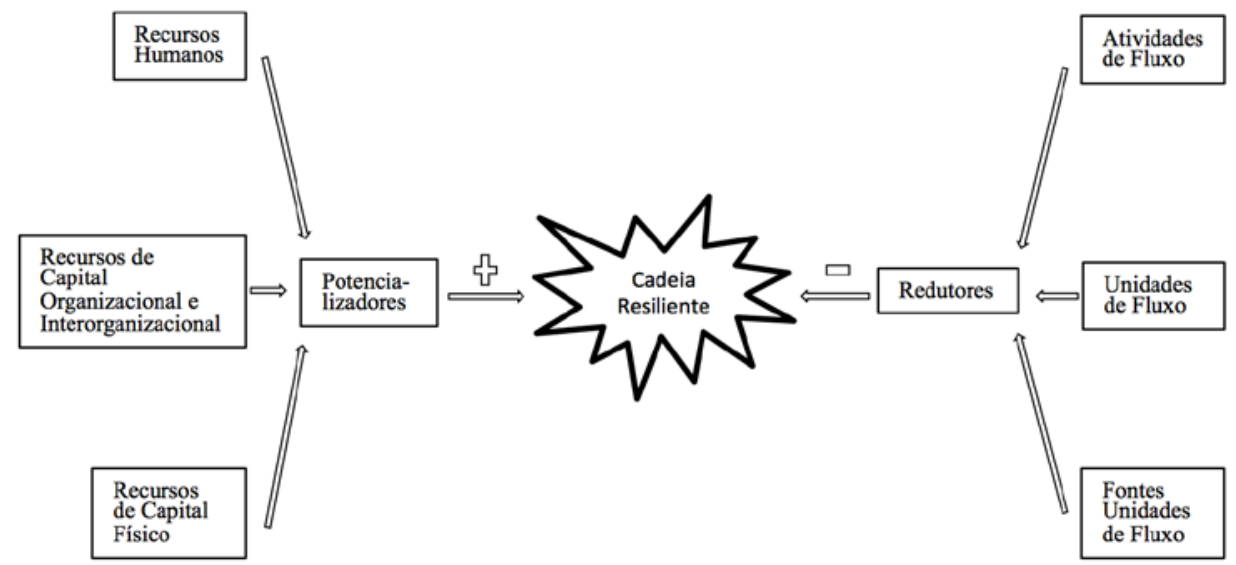

Figura 2 - Framework de Cadeias de Suprimento Resilientes (Blackhurst et al., 2011) 


\subsubsection{Potencializadores de Resiliência}

\section{Recursos Humanos}

Há uma variedade de fatores de capital humano (Becker, 1964) que podem aumentar a resiliência da Cadeia de Suprimentos. Esses fatores envolvem conhecimento e treinamento dos funcionários; a compreensão do custo total da gestão da cadeia de abastecimento; bem como a capacidade de realizar uma análise efetiva após a interrupção da cadeia. O treinamento de gestores da cadeia de suprimentos é primordial para saber quando é apropriado agir em casos de interrupções na cadeia.

\section{Recursos organizacionais e interorganizacionais}

Estes fatores centram-se em ativos intangíveis, tais como as interações entre os grupos dentro da empresa e as relações entre a própria empresa e outras empresas da cadeia de abastecimento (Barney, 1991). Recursos de capital organizacional e interorganizacional podem ser destacados como redes bem definidas de comunicação, equipes de gestão de risco interfuncionais (equipes formadas por profissionais com diferentes expertises), planos de contingência pré-definidos, parcerias com programas aduaneiros e criação de planos de diversificação de entrada em novas fronteiras, e o desenvolvimento de programas de gestão de relacionamento com fornecedores.

\section{Recursos de Capital Físico}

Esses fatores consistem em ativos tangíveis e incluem o uso do estoque de segurança, de tecnologias que aumentam a visibilidade na cadeia de suprimentos, sistemas que a monitoram e preveem áreas fracas, a capacidade de gerenciar riscos em nós individuais, isto é, antever interrupções e a capacidade para redesenhar rapidamente a cadeia de suprimentos quando ocorrerem avarias. Pode-se destacar a utilização de estoques de segurança como uma estratégia fundamental para mitigar o impacto das interrupções (Ho, 1992), pois há a redução da probabilidade de vendas perdidas devido a ruptura do estoque.

\subsubsection{Redutores de Resiliência}

\section{Atividades de fluxo}

Fatores relacionados ao fluxo de material entre os nós pode significativamente reduzir a resiliência da rede de alimentação (Buckley, 1967; Svensson, 2003). Esses fatores incluem o número de nós na cadeia de suprimentos, a presença de regulamentos e questões de segurança e congestionamento de portos e restrições da capacidade dos navios.

\section{Unidades de fluxo}

Fatores relacionados ao produto em si (ou seja, a unidade de fluxo) também podem reduzir a resiliência do sistema (Bertalanffy, 1950). Esses fatores incluem a complexidade do produto, bem como os requisitos de qualidade e armazenagem rigorosos, tornando mais difícil o lançamento e a movimentação dos produtos através da cadeia de suprimentos.

\section{Fonte de unidades de fluxo}

Esses fatores incluem a volatilidade da localização do fornecedor e as questões relacionadas ao trabalho e capacidade de produção na fábrica do fornecedor. Fornecedores localizados em áreas propensas a risco e/ou que estão geograficamente agrupados aumentam a probabilidade de interrupções dentro de uma cadeia de suprimentos. Além disso, restrições à capacidade de um fornecedor para produzir bens, que inclui a capacidade de produção e disponibilidade de trabalho, também afeta a resiliência da cadeia. 


\section{GESTÃO DE RISCOS - ESTUDO DE CASO NA EMPRESA X}

Este capítulo apresenta a Gestão de Riscos em uma Usina da Empresa X e também uma análise da importância de toda empresa possuir um processo estabelecido para gestão de riscos com enfoque pragmático e que agregue valor ao negócio. Além disso, esse capítulo destaca os diferentes impactos ambientais gerados pela agroindústria, apresentando as tecnologias utilizadas, os riscos que esse setor representa para os recursos naturais, seus principais resíduos e sua utilização alternativa ao descarte predatório.

\subsection{MAPEAMENTO DOS RISCOS NA CADEIA DE SUPRIMENTOS DA USINA NA EMPRESA $X$}

A metodologia de gestão de riscos da Empresa X contempla três etapas, detalhadas nas seções seguintes: diagnósticos dos riscos; priorização dos riscos; e mitigação dos riscos.

Uma maneira de conduzir a etapa de diagnósticos dos riscos de maneira eficiente consiste em definir os processos críticos, como a cadeia de suprimentos, os processos financeiros (tesouraria), os processos de comercialização e venda (geração da receita). Ou então as áreas sensíveis, como suprimentos, comercial, vendas, marketing, logística, tesouraria, recursos humanos, central de serviços compartilhados. Uma vez identificadas as fragilidades e vulnerabilidades do ambiente, parte-se para a identificação dos riscos potenciais.

Diante de um cenário com diversos riscos potenciais identificados, é necessário que se saiba como priorizá-los. Afinal a gestão de riscos tem que gerar valor ao negócio e não necessariamente todo risco identificado vale a pena ser mitigado, especialmente quando não existe uma relação satisfatória de custo-benefício.

Uma vez conhecidos e priorizados os riscos da empresa, a etapa seguinte consiste em definir e desenvolver as soluções pragmáticas para mitigá-los, ou seja, reduzir a exposição dos resultados e a sustentação e perenização do negócio.

A partir do modelo de Gestão de Riscos acima descrito, será apresentado como a Empresa X o utiliza para gerir seus riscos. Este item refere-se ao primeiro passo da metodologia, o Diagnóstico dos Riscos.

Abaixo serão descritos detalhadamente os principais riscos mapeados pela empresa em questão, apontando suas causas e consequências, assim como o grau de risco representado por ele.

\section{Plano de continuidade do negócio}

O Plano de Continuidade de Negócios (PCN) é uma ferramenta fundamental para que uma organização reconheça e responda de forma adequada eventuais ocorrências não rotineiras e que provoquem interrupções de suas atividades. O seu principal objetivo é estabelecer as diretrizes para que as próprias áreas determinem suas atividades críticas, sendo responsáveis pela confecção, atualização, testes e guarda dos respectivos PCNs.

Na Empresa X não existe um plano documentado e divulgado considerando todos os cenários de todas as usinas para lidar com considerável ruptura da operação. Não existe também um comitê de crises formal para lidar com eventuais acidentes de grande porte e a relação com imprensa e público.

A empresa em questão possui 13 usinas espalhadas pelo Brasil. E por uma questão de custo-benefício, não é possível considerar acidentes naturais em todos os campos de produção porque é difícil mapear todas as influências externas sobre a usina e, portanto os planos de contingências não cobrem $100 \%$ dos riscos. O plano de ação considerado neste contexto é analisar os PCNs existentes e verificar se os mesmos se adequam ao negócio da organização. 


\section{Reputação da empresa}

Uma vez que no Brasil acidentes ambientais de grande porte são raros e alguns até imprevisíveis (temporais, enchentes), o investimento em um comitê de crises formal não é justificável, sendo assim não seria possível proteger a imagem da empresa de forma $100 \%$ efetiva diante de um eventual desastre.

\section{Disponibilidade e controle de estoques de cana-de-açúcar}

Grande dependência de terceiros, novos entrantes no mercado e competição com outras culturas podem diminuir suprimento da matéria-prima. Além disso, desastres ecológicos, como pragas, enchentes e secas, queima acidental da cana (fora do período certo), tombamento de caminhões, falhas no monitoramento do teor de sacarose e excesso de chuva no plantio podem comprometer a produção, colheita e disponibilidade de cana-de-açúcar. Em relação ao estoque de cana-de-açúcar, podem-se encontrar riscos diversos no seu controle e salvaguarda tanto a granel como ensacado nas usinas e nos depósitos de terceiros. Há também riscos de perda de estoque em trânsito, isto é, quando estão sendo transportados para seus destinos ou para outros locais de armazenamento.

\section{Relação com os fornecedores}

Uma eventual crise na produção de cana-de-açúcar pode ocasionar desgastes e crises nas relações com clientes B2B ("Business to business"), nomenclatura usada quando duas empresas fazem negócios entre si, e B2C ("Business to costumer"), sigla usada quando a relação comercial se dá entre a empresa e o consumidor final.

\section{Disponibilidade de mão-de-obra}

Investimento em mão de obra é preciso para sustentar o crescimento da operação. Esse fator é especialmente crítico em terras do campo, onde muitas vezes a mão de obra precisa ser desenvolvida, assim como a infraestrutura urbana mais próxima. No período de colheita, em municípios onde a atividade é importante economicamente, uma grande quantidade de mão de obra volante e, geralmente, desqualificada migra para essas cidades. Tal situação exige que os setores de promoção social das agroindústrias, e muitas vezes, dos municípios tenham que efetuar medidas que possam tornar a permanência desses indivíduos o menos impactante possível para o meio ambiente e para o meio urbano, uma vez que a infraestrutura de tais municípios não é suficiente para os novos moradores.

\section{Aquisições de novas usinas}

Alta competição de grandes empresas para aquisição de usinas, limitando a oferta de usinas de qualidade/tamanho atrativos e aumentando o preço de compra. Mais usinas levam a mais unidades para serem monitoradas, a novos ambientes e a novos riscos, além disso, tornase um novo ponto de atração para os trabalhadores durante a safra e, por isso, devem haver maiores cuidados e precauções com eles, suas famílias e com os municípios em volta.

\section{Expansão da cogeração}

Pode haver limitação da expansão da cogeração devido a tendência de preços baixos nos leilões governamentais, o que inviabiliza economicamente os lugares de baixa/média capacidade de moagem que também necessitam de altos investimentos por usina. Há ainda risco de faltar matéria prima para cogeração. Além do volume de bagaço da empresa não ser suficiente para a geração de energia prevista no ano, há a possibilidade de existir no médio/longo prazo uma competição pela matéria prima para diferentes fins (ex. álcool de $2^{\mathrm{a}}$ geração, pellets). Quanto mais usinas estiverem cogerando, menos bagaço terão disponível para venda e com preços mais elevados. Existe também um forte risco de menor disponibilidade de cana nas safras seguintes, o que é especialmente crítico em contratos de longo prazo. 


\section{SSMA (Saúde, Segurança e Meio Ambiente)}

Saúde e Segurança referem-se aos riscos de acidentes no campo, como transporte de trabalhadores rurais e fluxo de máquinas, ou de acidentes dentro das usinas, que podem ser incêndios, explosões, problemas com o maquinário ou perturbações no armazém;

Meio Ambiente envolve a regulamentação ambiental e a fiscalização que realizam visitas periódicas nas unidades produtivas.

\section{Plano de Investimentos - cumprimento de prazo e orçamento}

Os riscos estão na possibilidade de variação de premissas macroeconômicas; alteração de pessoas dentro de um projeto, especialmente os de longo prazo; variação de escopo pósaprovação; e contratação de recursos muito em cima do início das atividades.

\section{Escoamento da produção}

Dependência do porto de Santos, uma que vez que há ausência de alternativa para escoamento.

\section{Queima da cana-de-açúcar}

A prática da queima da cana, como facilitador do processo de colheita, é largamente utilizada em todo o país. Trata-se de uma técnica que permite o aumento da produtividade do trabalhador rural durante a colheita. Além disso, reduz o custo de carregamento da cana de açúcar do campo até a usina, aumentando a eficiência e o rendimento das moendas durante o processo inicial de processamento na indústria.

\section{Elaboração da Matriz de Risco}

Realizar o diagnóstico de riscos e definir suas probabilidades é uma etapa importante no modelo de gestão de riscos da Empresa X. Avaliar os fatores de risco é uma medida crucial para qualquer modelo de Gerenciamento do Risco Corporativo que envolva Cadeias de Suprimentos. O método que a Empresa X usa para realizar tal avaliação é a Matriz de Risco, representada na Figura 3.

Algumas das vantagens dessa representação matricial é o alto poder de comunicação visual, indicando, a partir de sinalizadores (verde, amarelo ou vermelho) o nível de impacto do risco, além de ser simples, de fácil elaboração e gestão. A Matriz de Risco apresentada na Figura 3 foi elaborada estimando a probabilidade de ocorrência dos riscos diagnosticados versus o impacto monetário dos mesmos e o nível relativo de gestão que cada risco mapeado demanda. Os níveis podem ser classificados como alto, médio ou baixo de acordo com as cores verde, amarela ou branca respectivamente. 


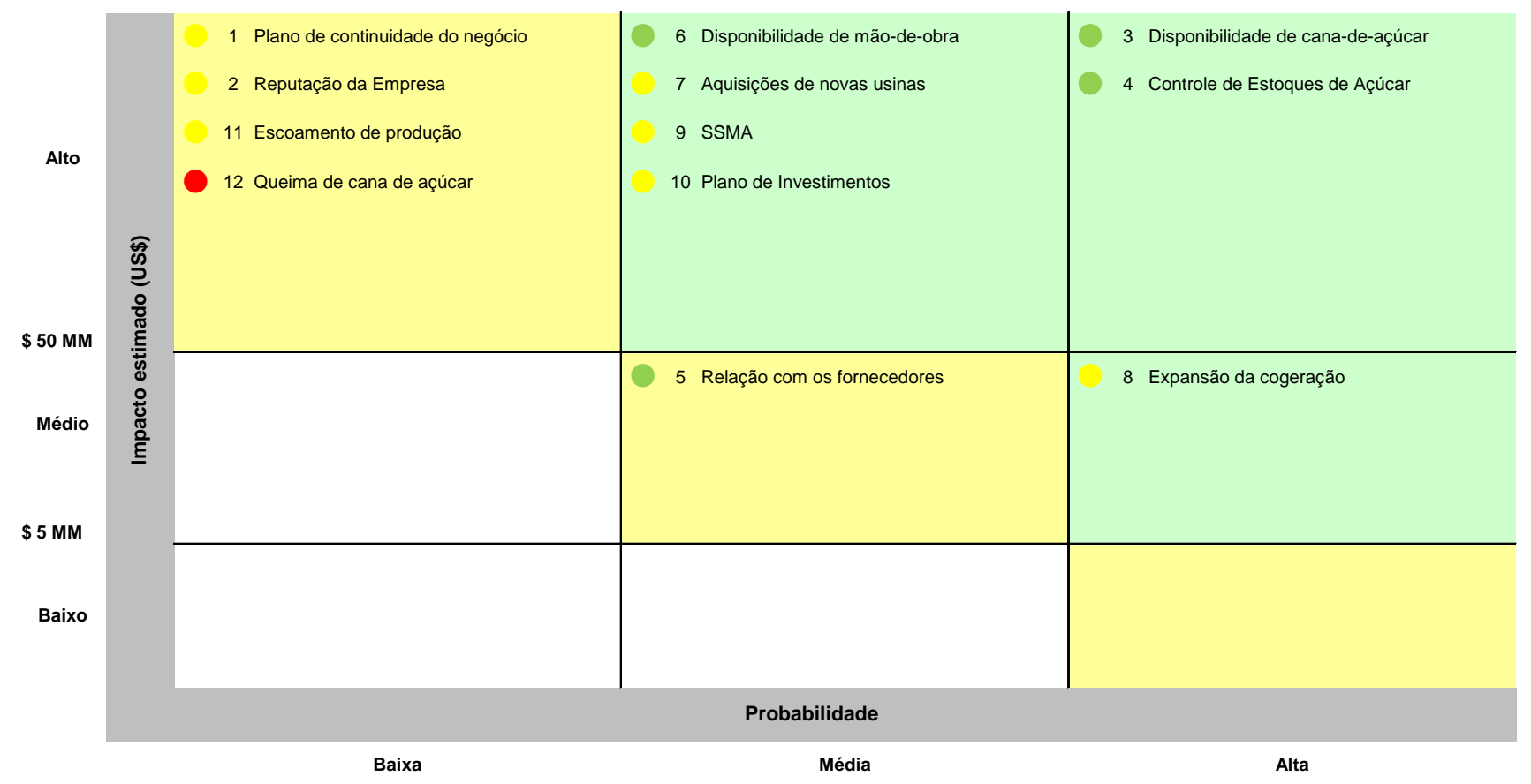

Legenda

\begin{tabular}{|l||c|c|c|}
\hline $\begin{array}{c}\text { Nível de aceitabilidade do risco } \\
\text { Risco aceitável }\end{array}$ & M & A & A \\
\cline { 2 - 4 } $\begin{array}{l}\text { Risco requer melhorias } \\
\text { Risco requer grandes melhorias }\end{array}$ & B & M & A \\
\cline { 2 - 4 } & B & B & M \\
\hline
\end{tabular}

Figura 3 - Matriz de Risco da Empresa X (Material fornecido pela empresa)

\subsection{ANALISANDO O NÍVEL DE RESILIÊNCIA DA EMPRESA $X$}

Como mencionado no item 2.2. (Construindo uma Cadeia de Suprimentos Resiliente), a ideia da matriz resumo (Figura 3) é que os gestores possam resumir suas avaliações nessa matriz quanto à resiliência dos processos, sendo que cada quadrante captura um nível de resiliência inerente à cadeia, e mais importante, poderia servir de base para priorizar os esforços necessários na construção de resiliência. Mas, para definir os níveis de redutores e potencializadores, é preciso primeiro ter uma visão global da Cadeia de Suprimentos que rege a empresa e mapear quais fatores são redutores e quais são potencializadores de resiliência. Com base no framework (figura 2) e em entrevistas realizadas com colaboradores da Empresa $\mathrm{X}$, tais fatores foram detalhados, assim como seus níveis de influência na Cadeia da Empresa.

Nas tabelas 1 e 2 abaixo estão resumidas as principais características de uma Cadeia de Suprimentos, as que estão marcadas com "x" são aquelas que influenciam na Cadeia de Suprimentos da Empresa X. 


\begin{tabular}{|l|c|}
\hline \multicolumn{1}{|c|}{ Recursos humanos } & Empresa X \\
\hline $\begin{array}{l}\text { Educar e treinar os funcionários para executar os planos de contingência } \\
\text { da cadeia de suprimentos }\end{array}$ & $\mathrm{x}$ \\
\hline $\begin{array}{l}\text { Compreensão do funcionário quanto ao custo-benefício dos trade-offs } \\
\text { quando este está gerenciando os riscos da cadeia de suprimentos }\end{array}$ & $\mathrm{x}$ \\
\hline \multicolumn{1}{|c|}{ Capacidade de executar a análise de interrupções na cadeia } & $\mathrm{x}$ \\
\hline Recursos organizacionais e interorganizacionais & Empresa X \\
\hline Protocolo de comunicação definido & $\mathrm{x}$ \\
\hline Plano de Contingência definido & $\mathrm{x}$ \\
\hline $\begin{array}{l}\text { Parceria com programas de taxas alfandegárias (C-TPAT) e/ou } \\
\text { desenvolvimento de planos de diversificação }\end{array}$ & $\mathrm{Empresa} \mathrm{X}$ \\
\hline $\begin{array}{l}\text { Desenvolvimento de programas de gestão para relacionamento com } \\
\text { fornecedor }\end{array}$ & $\mathrm{x}$ \\
\hline & $\mathrm{x}$ \\
\hline Uso de estoque de segurança & \\
\hline Aumento da visibilidade da cadeia de suprimentos & \\
\hline $\begin{array}{l}\text { Relatórios de exceção e ferramentas de prevenção para fácil detecção do capital físico } \\
\text { problema impedindo a interrupção da cadeia }\end{array}$ & $\begin{array}{l}\text { Sistemas de monitoramento de riscos para cada nodo da cadeia de } \\
\text { suprimentos }\end{array}$ \\
\hline Capacidade de redesenhar rapidamente a cadeia de suprimentos & \\
\hline
\end{tabular}

Tabela 1 - Potencializadores de Resiliência da Empresa X

\begin{tabular}{|c|c|}
\hline Atividades de fluxo & Empresa X \\
\hline Quantidade de nós na cadeia de suprimentos & $x$ \\
\hline \multicolumn{2}{|l|}{ Rigorosos regulamentos alfandegários e questões de segurança } \\
\hline Congestionamento de navio e portos / restringindo a capacidade & $x$ \\
\hline Unidades de fluxo & Empresa X \\
\hline \multicolumn{2}{|l|}{$\begin{array}{l}\text { Complexidade dos produtos (número e exclusividade de peças e } \\
\text { necessidade de propriedade tecnológica) }\end{array}$} \\
\hline Requer rigorosos controles de qualidade de armanezamento & $\mathrm{x}$ \\
\hline Fonte de unidades de fluxo & Empresa $\mathrm{X}$ \\
\hline $\begin{array}{l}\text { Volatilidade da localização do fornecedor (por exemplo incertezas } \\
\text { políticas ou desastres naturais como risco de tsunami) e/ou grupo de } \\
\text { fornecedores diversos }\end{array}$ & $\mathrm{x}$ \\
\hline $\begin{array}{l}\text { Limitações do fornecedor - capacidade de produção e disponibilidade de } \\
\text { trabalho }\end{array}$ & $x$ \\
\hline
\end{tabular}

Tabela 2 - Redutores de Resiliência da Empresa X

\subsection{CLASSIFICAÇÃO DO NÍVEL DE RESILIÊNCIA DA EMPRESA X}

A partir do estudo realizado acima foi possível investigar detalhadamente a cadeia de suprimentos da Empresa X e, a partir disso, concluir qual o seu nível de resiliência. A tabela 1 revela que a Empresa $\mathrm{X}$ tem 9 dos 12 potencializadores de resiliência, o que corresponde a $75 \%$ do total, e pode ser considerado um alto nível deste fator. Já a tabela 2 mostra que a empresa tem 5 dos 7 redutores de resiliência, ou seja, em torno de $71 \%$ do total, indicando que ela também possui um alto nível deste outro fator.

Sendo assim, podemos relacionar as análises à Matriz de Nível de Resiliência da figura 1 e classificar a cadeia de suprimentos da Empresa $\mathrm{X}$ como Volátil. Isso significa que ela apresenta uma cadeia de suprimentos com alto nível para ambos os fatores redutores e potencializadores de resiliência. Neste caso, os gestores devem focar seus esforços em mitigar os redutores de resiliência, a fim de aumentar a resiliência da sua cadeia e alcançar o primeiro quadrante (Cadeia de Suprimentos Resiliente). 


\section{CONCLUSÃO}

Este trabalho destacou os riscos para a continuidade dos negócios que se encontram em cadeia de suprimentos em geral e realizou um estudo de caso na Empresa X, cujas áreas de atuação são: produção de etanol, açúcar e bioenergia; e distribuição de combustíveis. As tendências para a criação de redes cada vez mais complexas de organizações interdependentes têm aumentado alguns destes riscos. Neste caso, aumenta a necessidade de organizações rastrearem e mapearem os riscos sistêmicos das suas cadeias de suprimentos e se concentrarem na busca de melhorias de eficiência através de estratégias e soluções simples e baratas que as tornem cada vez mais competitivas e adaptáveis às mudanças do mercado. Foi argumentado que a prioridade para planejamento de negócios deve ser a busca por um nível cada vez mais alto de resiliência, o que implica em maior flexibilidade e agilidade.

A partir de uma revisão bibliográfica, foram identificados métodos para medir a resiliência de uma empresa, tais como a Matriz de Nível de Resiliência e o framework de Cadeias de Suprimentos Resiliente. Ambos foram empregados na análise do nível de resiliência da empresa estudada.

A metodologia de mapeamento de riscos da Empresa $\mathrm{X}$ foi detalhada, considerando seus riscos eminentes e os impactos que podem causar. As ameaças à sua cadeia de suprimentos envolvem os seguintes fatores: plano de continuidade do negócio; reputação da empresa; disponibilidade e controle de estoques de cana-de-açúcar; relação com os fornecedores; disponibilidade de mão-de-obra; aquisições de novas usinas; expansão da cogeração; SSMA (Saúde, Segurança e Meio Ambiente); Plano de Investimentos cumprimento de prazo e orçamento; e escoamento da produção.

Mediante as análises da influencia dos fatores supracitados, conclui-se que a Empresa $\mathrm{X}$ apresenta um nível de resiliência Volátil, o que significa que apesar de ter um grande número de potencializadores de resiliência, sofre influência de um grande número de redutores da mesma. Isso significa que seus gestores devem aumentar seus esforços na estruturação planos e subterfúgios para mitigar tais redutores de resiliência do seu negócio, como reduzir o número nós nas cadeias de suprimentos, procurar alternativas de escoamento para exportação, manter o um rigoroso controle de qualidade do armazenamento dos seus produtos que são perecíveis, manter um relacionamento com fornecedores alternativos e estar preparada para limitações de seus fornecedores.

Com o estudo feito foi possível concluir que a busca pela otimização da resiliência nas cadeias de suprimentos nas empresas deve ser contínua. Por ser um assunto amplo, porém pouco explorado, com um portfólio de pesquisas ainda em construção não há metodologias que indiquem como alcançar o nível máximo de resiliência. Sendo assim, um próximo passo seria explorar mais a fundo as metodologias existentes e a partir disso desenvolver métodos capazes de conduzir os gestores para o alcance do nível de resiliência desejado a sua cadeia de suprimentos.

\section{REFERÊNCIAS BIBLIOGRÁFICAS}

[1] Barney, J. 1991. "Firm Resources and Sustained Competitive Advantage." Journal of Management 17(1):99-121.

[2] Becker, G. 1964.Human Capital. New York: Columbia.

[3] Bertalanffy, L. 1950. “An Outline of General System Theory.” The British Journal for the Philosophy of Science 1(2):134-65.

[4] Blackhurst, J., Dunn, K.S.; Craighead, C.W. 2011.“An Empirically Derived Framework of Global Supply Resiliency.”Journal of Business Logistics, 32(4), 374-391.

[5] Buckley, W. 1967. Sociology and Modern Systems Theory. Upper Saddle River, NJ: Prentice Hall.

[6] Christopher, M. e Peck, H., 2004. "Building the resilient Supply Chain.” International 
Journal of Logistics Management, 15 (2), 1-13.

[7] Faisal, Mohd. Nishat., Banwet, D. K. and Shankar, R. 2006. "Supply Chain Risk Mitigation: Modeling the Enablers”, Business Process Management Journal, Vol. 12 No. 4, pp. 535-552.

[8] Ho, C.J. 1992. “An Examination of a Distribution Resource Planning Problem: DRP System Nervousness.” Journal of Business Logistics 13(2):125-52.

[9] Norman, A., and Jansson, U. 2004. "Ericsson's Proactive Supply Chain Risk Management Approach After a Seri- ous Sub-Supplier Accident.” International Journal of Physical Distribution and Logistics Management 34(5):434-56.

[10] Sheffi, Y., and Rice, J.B. 2005. "A Supply Chain View of the Resilient Enterprise.” MIT Sloan Management Review 47(1):41-48.

[11] Svensson, G. 2000. "A Conceptual Framework for the Anal- ysis of Vulnerability in Supply Chains." International Journal of Physical Distribution and Logistics 30(9):731- 749.

[12] Svensson, G. 2003. "The Principle of Balance Between Companies' Inventories and Disturbances in Logistics Flows." International Journal of Physical Distribution and Logistics Management 33(9):765-84.

[13] Zolkos, R., 2003. Attention to supply-chain risks grows. Business Insurance, 37 (30), 45.

[14] Zsidisin, G., Melnyk, S., and Ragatz, G. 2005. “An Institutional Theory Perspective of Business Continuity Planning for Purchasing and Supply Management.” International Journal of Production Research 43(16):3401-20. 